\title{
Quantitative analysis of factors that affect oil pipeline network accident based on Bayesian networks: A case study in China
}

\author{
Chao Zhang ${ }^{1, *}$, Ting Xin $\mathrm{QIN}^{1}$, Shuai Huang ${ }^{1}$, Jian Song $\mathrm{Wu}^{2}$, and Xin Yan Meng ${ }^{1}$ \\ ${ }^{1}$ China National Institute of Standardization, 100191 Beijing, China \\ ${ }^{2}$ School of Resources and Safety Engineering, China University of Mining and Technology, 100083 Beijing, China
}

\begin{abstract}
Some factors can affect the consequences of oil pipeline accident and their effects should be analyzed to improve emergency preparation and emergency response. Although there are some qualitative analysis models of risk factors' effects, the quantitative analysis model still should be researched. In this study, we introduce a Bayesian network (BN) model of risk factors' effects analysis in an oil pipeline accident case that happened in China. The incident evolution diagram is built to identify the risk factors. And the BN model is built based on the deployment rule for factor nodes in $\mathrm{BN}$ and the expert knowledge by Dempster-Shafer evidence theory. Then the probabilities of incident consequences and risk factors' effects can be calculated. The most likely consequences given by this model are consilient with the case. Meanwhile, the quantitative estimations of risk factors' effects may provide a theoretical basis to take optimal risk treatment measures for oil pipeline management, which can be used in emergency preparation and emergency response.
\end{abstract}

\section{Introductions}

Oil pipelines are used more and more widely and their accidents may result in serious consequences. Several types of factors, including hazard property, environment condition, hazard-affected carriers and emergency response, can affect oil pipelines accident consequences. The effect of these factors should be analyzed to identify their importance. And furthermore, the optimal risk treatment plan which can reduce the probability and consequences of an accident, can be developed based on the effect analysis.

Researchers have developed some models to analyze the effect of risk factors. Some diagram methods, including fault tree models, event tree models and bowtie models, are effective to analyze these factors qualitatively. The risk factors can be identified by these diagram methods but it's difficult for quantitative analysis. Incident simulation models can analyze the factor effect quantitatively. But the simulation and calculation are complex and it's difficult to refer all the risk factors in a simulation model. Bayesian network $(\mathrm{BN})$ is an effective method for probabilistic analysis and diagnose analysis and has been used to analyze oil accident issues.

In this paper, an integrated model is established to analyze the risk factors' effects of an oil pipeline accident. An oil pipeline accident case that happened in China has been taken as an example. Risk factors are identified qualitatively by the incident evolution diagram. Then they are deployed as the nodes deployment rule of $\mathrm{BN}$ model and initialed according to the conditional probabilities given by statistics and experts' estimation. Based on the BN model of this oil pipeline accident, the effects of risk factors can be analyzed quantitatively and the consequences can be predicted according to the most likely consequence situations.

\section{Quantitative Analysis Model of an Accident Case}

\subsection{A Brief Description of Oil Pipeline Accident Case}

An oil pipeline explosion accident case has been taken as the example because it refers to some important risk factors. The accident occurred at 10:25 p.m., Nov. 22, 2013, in an industrial district in Qingdao city, Shandong province in China. An oil pipeline broke, and the oil leaked into a municipal drainage culvert. Because the leakage to the culvert was not observed, the oil gas density increased continuously until it exploded; 62 people died, 136 were injured and more than 75 million RMB was lost in this explosion accident.

\subsection{Identify Risk Factors Based on Incident Evolution Diagram}

An incident evolution diagram is built to identify risk factors. This diagram comprises five kinds of nodes: $\mathrm{Si}$ (incident Situation), Ei (key Environment condition), Ti (emergency Target), Mi (response Mission) and $\mathrm{Ci}$ (consequence). The initial incident state $\mathrm{S} 1$ means the

\footnotetext{
* Corresponding author: zhangchao@cnis.gov.cn
} 
incident occurs. Different environment condition Ei will lead to different $\mathrm{Si}$. The emergency response target $\mathrm{Ti}$ is fixed to address the incident situation $\mathrm{Si}$, and the mission that needed to be executed is $\mathrm{Mi}$. If the target $\mathrm{Ti}$ is achieved, the final consequence $\mathrm{Ci}$ will occur in the condition that $\mathrm{Ti}$ is the final emergency target.
The incident evolution diagram for the oil pipeline accident case is shown in Figure 1. We can see that the environment condition ( $E_{1}$-confined space \& $E_{2}$-water area) will lead to serious consequences $\left(C_{2}\right.$-ground and water pollution \& $C_{4}$-explosion, casualties, economic loss). Meanwhile, emergency management $\left(M_{1}, M_{2}, M_{3}\right.$ and $M_{4}$ ) can affect consequences obviously.

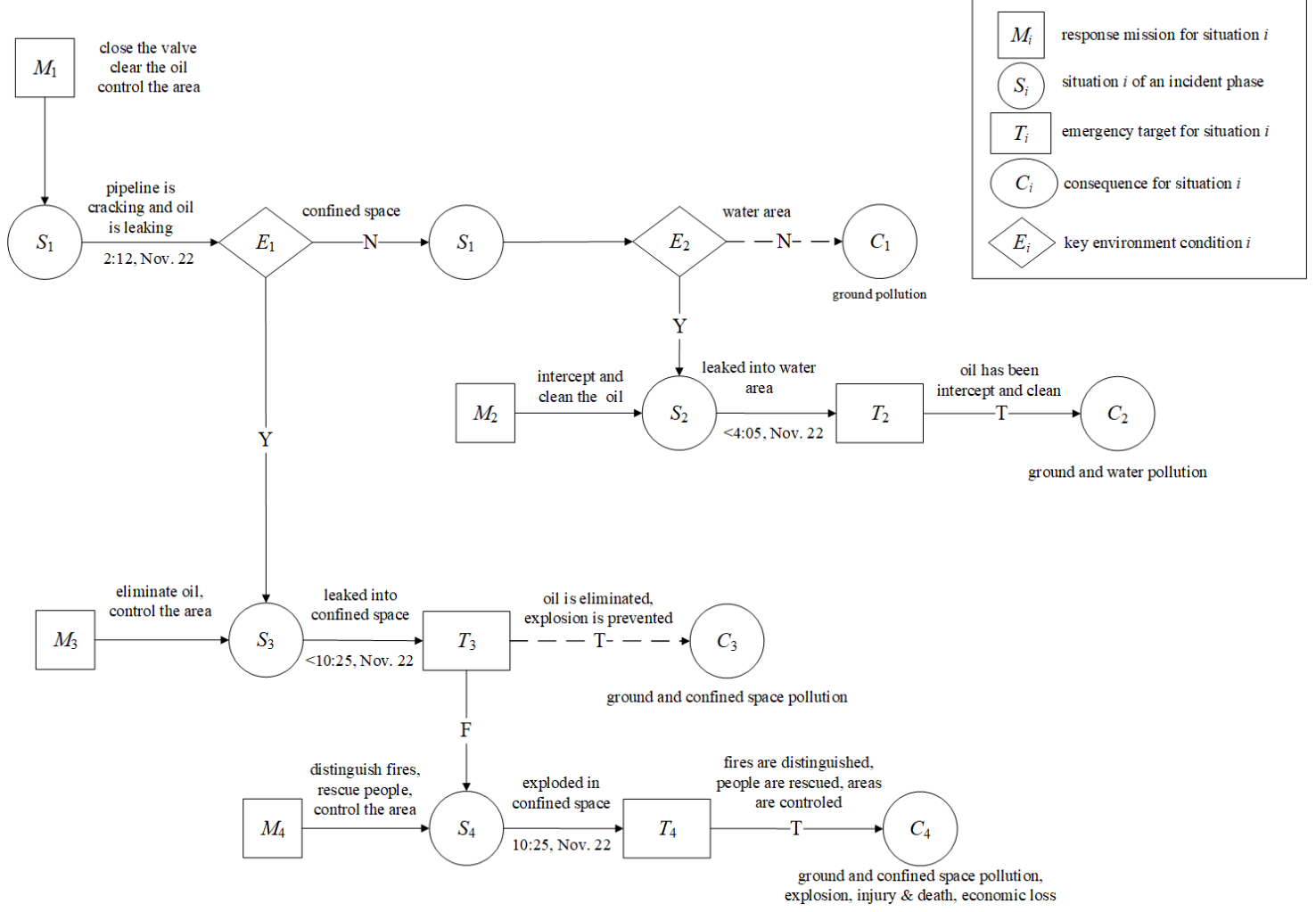

Fig. 1. Incident Evolution Diagram of the Oil Pipeline Accident Case

\subsection{Factor Effect Analysis Based on Bayesian Network}

\subsubsection{Bayesian Network Method}

The basic of $\mathrm{BN}$ is Bayesian condition probability theory. It contains conditional independence and joint probability distribution:

$$
\begin{aligned}
& P\left(V_{1}, V_{2}, \mathrm{~L}, V_{k} / v\right)=\prod_{1}^{k} P\left(V_{i} / v\right)(i=1,2, \mathrm{~L}, k) \\
& P\left(V_{1}, V_{2}, \mathrm{~L}, V_{k} / v\right)=\prod_{1}^{k} P\left(V_{i} / \operatorname{Parent}\left(V_{i}\right)\right)(i=1,2, \mathrm{~L}, k)
\end{aligned}
$$

Where $V_{1}, V_{2}, \ldots, V_{k}$ represent various variables, $v$ is the normal node, which facilitates the expression of the conditional probability, and $\operatorname{Parent}\left(V_{i}\right)$ is the parent nodes of $V_{i}$.

\subsubsection{Dempster-Shafer Evidence Theory}

The Dempster-Shafer (DS) evidence theory is a method for quantitative analysis of system uncertainty. It can be used to calculate the conditional probabilities of $\mathrm{BN}$ factors 错误!未找到引用源。. In this BN model, the conditional probabilities of risk factors' are calculated based on DS theory according to experts' estimation.

\subsubsection{Bayesian Network Model for Oil Pipeline Accident}

For an oil pipeline accident, the risk factors may refer to environment, hazard, incident, hazard-affected carries, emergency response, and consequences. As an integrated effect analysis model, these risk factors nodes should be considered and deployed according to the nodes deployment rule of BN model as Figure 2. 


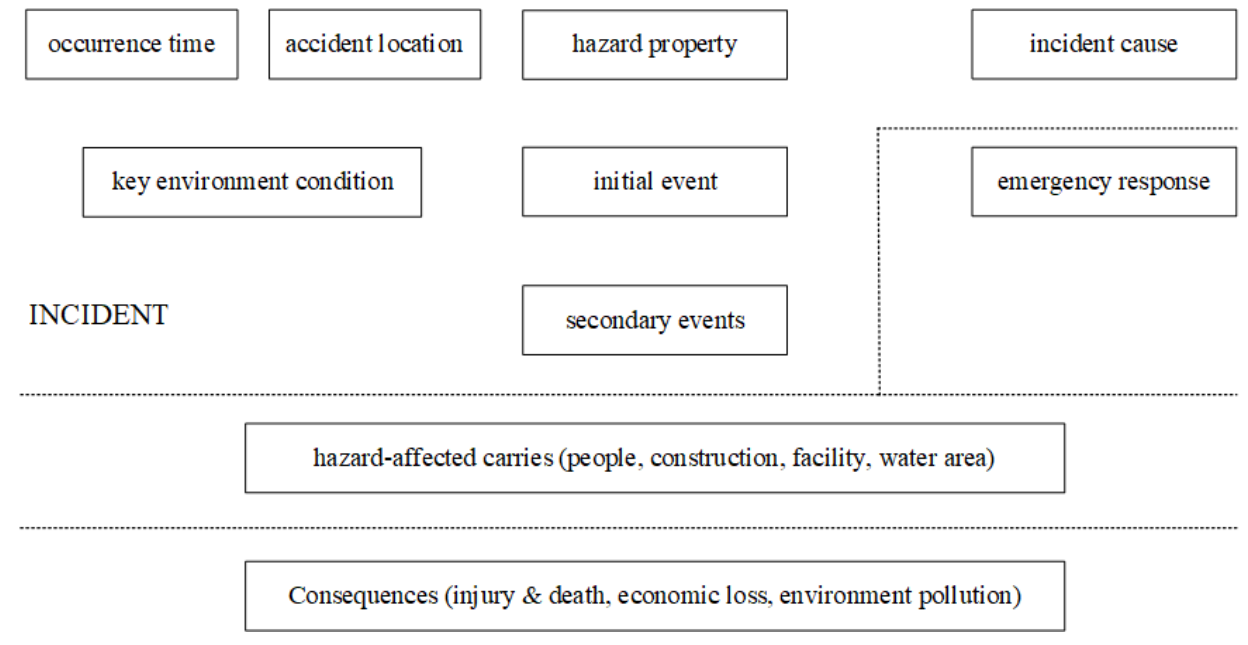

Fig. 2. Deployment Rule of the BN Nodes for an Oil Pipeline Accident

$\mathrm{BN}$ nodes include independent nodes and dependent nodes. The factors of occurrence time, accident location, hazard property (pipeline pressure, pipeline flux), incident cause and key environment condition (confined space nearby, water area nearby) are independent nodes. Their occurrence probabilities are based on experts' estimation and statistics. The factors of initial event, secondary events (flame and fire ball, water pollution), hazard-affected carries (threatened persons, buildings, infrastructure and lifeline), emergency response and consequences (casualties, economic loss, environment pollution) are dependent nodes. Their conditional probabilities are based on experts' estimation using DS methods. As the factor nodes have been identified and deployed, and the occurrence probability and conditional probability have been estimated, then the $\mathrm{BN}$ can be constructed as Figure 3. It is a snapshot by the BN software Netica. The effects of risk factors for consequences can be quantitative analyzed by this BN model.

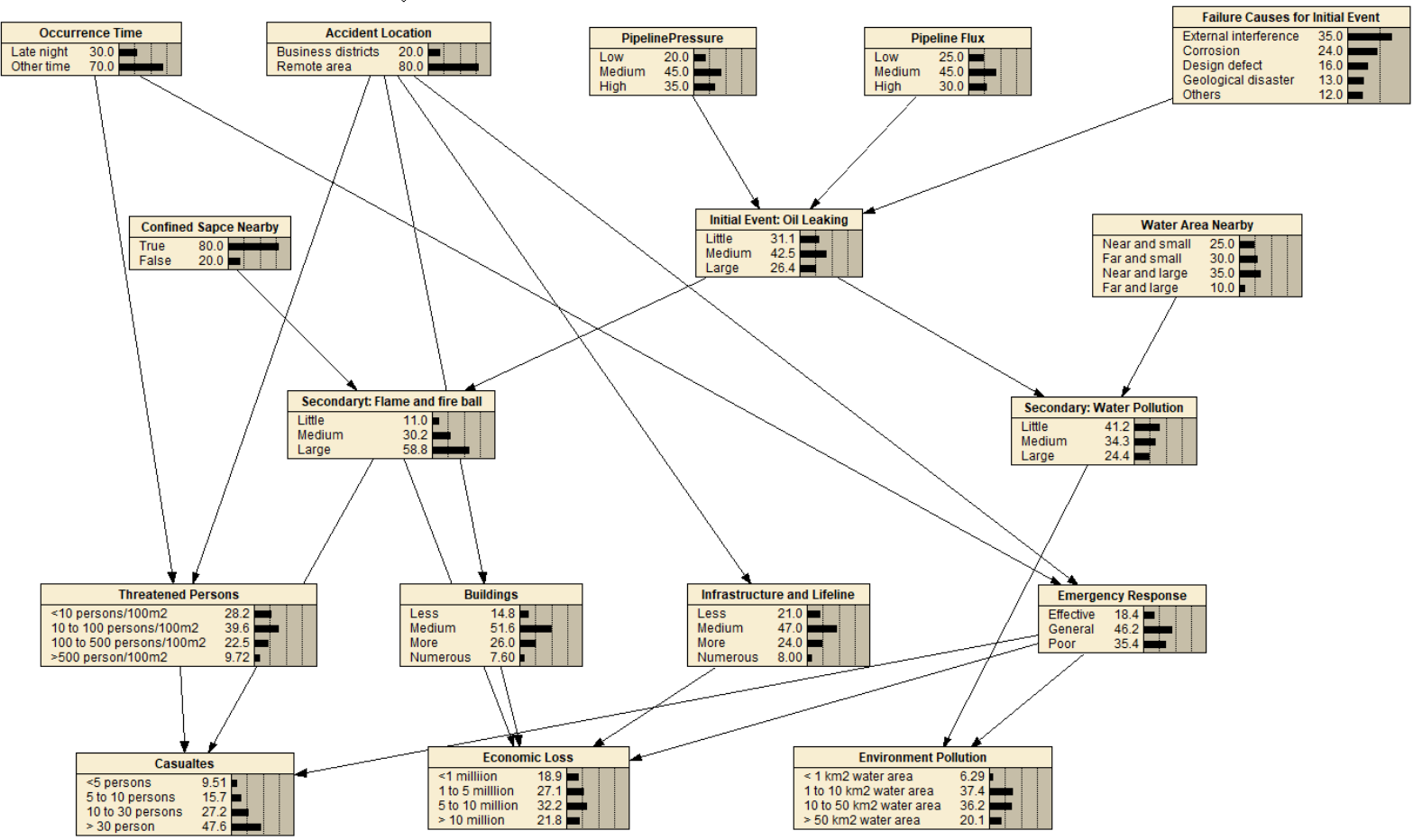

Fig. 3. The BN Model for the Oil Pipeline Accident Case

\section{Results and Discussion}

\subsection{Scenario Setting and Consequences Estimation}

As the basic of effect analysis, the situations of scenario nodes should be set according to the oil pipeline accident case. The situation setting of scenario nodes, including
Time \& Location nodes, Hazards Property nodes, Incident Case node, and Critical Environment Conditions nodes, are shown as Table 1, and the corresponding BN model is shown as Figure 4.

Table 1. Situation Setting of Scenario Nodes in the Oil Pipeline Accident.

\begin{tabular}{|c|c|}
\hline Scenario Node & $\begin{array}{c}\text { Situation } \\
\text { Setting }\end{array}$ \\
\hline
\end{tabular}

\footnotetext{
* Corresponding author: zhangchao@cnis.gov.cn
} 


\begin{tabular}{|l|l|l|}
\hline $\begin{array}{l}\text { Time \& } \\
\text { Location }\end{array}$ & $\begin{array}{l}\text { (1) Occurrence } \\
\text { Time }\end{array}$ & Late night \\
\cline { 2 - 3 } & $\begin{array}{l}\text { (2) Accident } \\
\text { Location }\end{array}$ & $\begin{array}{l}\text { Business } \\
\text { districts }\end{array}$ \\
\hline $\begin{array}{l}\text { Hazards } \\
\text { Property }\end{array}$ & $\begin{array}{l}\text { (1) Pipeline } \\
\text { Pressure }\end{array}$ & High \\
\cline { 2 - 3 } & $\begin{array}{l}\text { (2) Pipeline } \\
\text { Flux }\end{array}$ & High \\
\hline
\end{tabular}

\begin{tabular}{|l|l|l|}
\hline Incident Cause & $\begin{array}{l}\text { (1) Failure } \\
\text { Causes for } \\
\text { Initial Event }\end{array}$ & $\begin{array}{l}\text { External } \\
\text { Interference }\end{array}$ \\
\hline $\begin{array}{l}\text { Critical } \\
\text { Environment } \\
\text { Conditions }\end{array}$ & $\begin{array}{l}\text { 1) Confined } \\
\text { Space Nearby }\end{array}$ & True \\
\cline { 2 - 3 } & $\begin{array}{l}\text { (2) Water Area } \\
\text { Nearby }\end{array}$ & $\begin{array}{l}\text { Near and } \\
\text { large }\end{array}$ \\
\hline
\end{tabular}

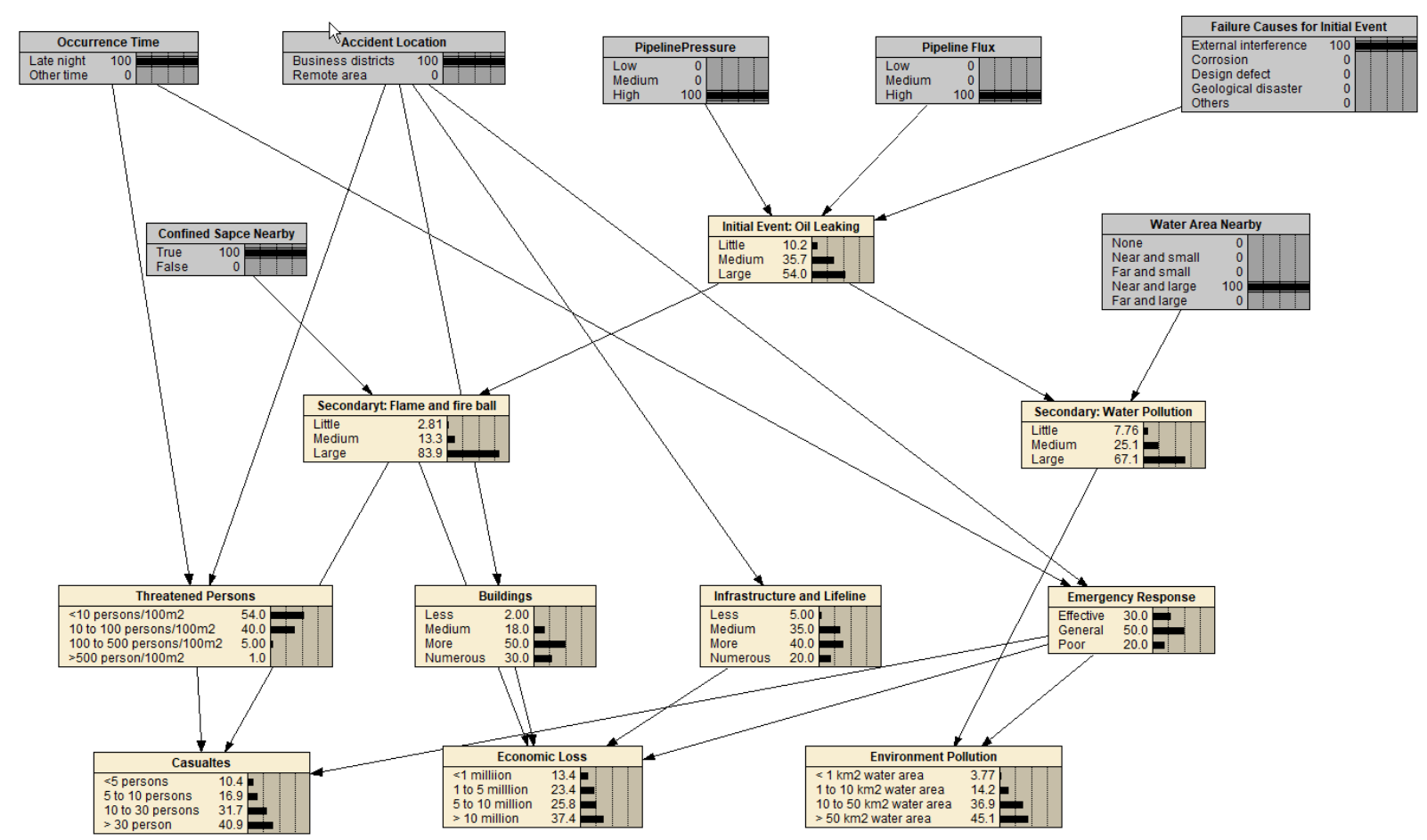

Fig. 4. The BN Model for the Oil Pipeline Accident Case Based on Scenario Setting

Figure 4 shows the most likely consequences are: more than 30 persons casualties, more than 10 million economic loss, and larger than $50 \mathrm{~km}^{2}$ water area pollution. They are consilient with the case. According to this oil pipeline accident case scenario, the effects of risk factors can be quantitative analyzed.

\subsection{Confined Space}

One of the key environment conditions is Confined Space Nearby. As the oil leaked into a municipal drainage, the oil gas density has been increasing continuously until it exceeded the explosion limit and the exploded. The explosion was so rapid and violent that it resulted in serious casualties and economic loss. The effects of Confined Space Nearby factors to Casualties and Economic Loss are shown as Figure 5.

Figure 5 shows the critical effect of Confined Space Nearby condition. Both of the most serious of Casualties ( $>30$ persons) and Economic Loss ( $>10$ million) will be predominant in condition that there is a confined space nearby. And the corresponding probabilities increases obviously. For Casualties, it increases from $26 \%$ to $40.9 \%$. And for Economic Loss, it increases from 20.8\% to $37.4 \%$.
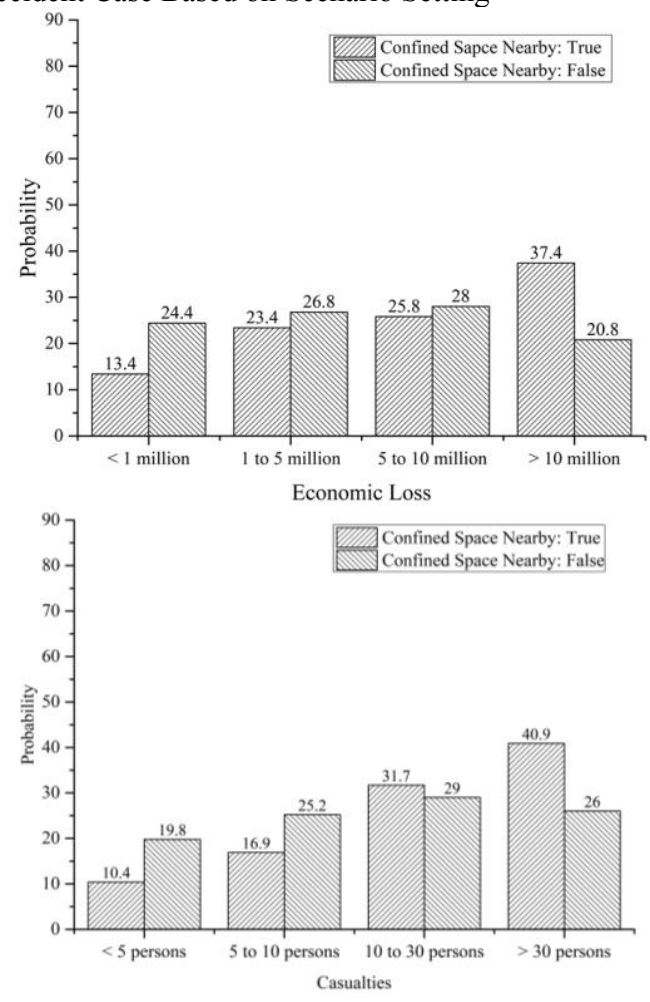

Fig. 5. Effects of Confined Space Nearby factors to Casualties and Economic Loss 


\subsection{Water Area}

It is more difficult to deal with the pollution in water than on land. Therefore, Water Area Nearby is another key environment condition. The water pollution will be easier in condition that the water area is nearer, and will be more serious in condition that the water area is larger. The effect of Water Area Nearby factor to Environment Pollution is shown as Figure 6.

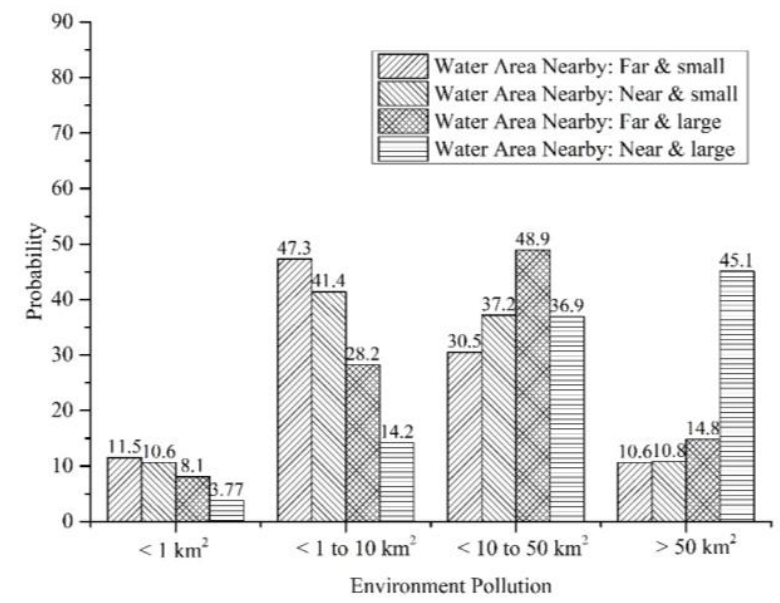

Fig. 6. Effect of Water Area Nearby factor to Environment Pollution

Figure 6 shows the critical effect of Water Area Nearby condition to Environment Pollution. Because the result of Initial Event Oil Leaking is Large $(54.0 \%$, as Figure 4), the probabilities of little environment pollution $\left(<1 \mathrm{~km}^{2}\right)$ is small $(3.77 \% \sim 11.5 \%)$. And the probability of the consequence " 1 to $10 \mathrm{~km}^{2}$ " is more than $40 \%$ both in "Far \& small" condition and "Near \& small" condition. It may result in serious water pollution if there is large water area near the incident site, especially for the consequence state " $>50 \mathrm{~km}^{2}$ ". The probability of the most serious environment pollution ( $>$ $50 \mathrm{~km}^{2}$ ) increases significantly from the condition "Far \& Large" (14.8\%) to "Near \& Large" (45.1\%).

\subsection{Emergency Response}

Emergency response aims to protect people, reduce economic loss and avoid environment pollution. It plays an important role for consequences because it can control the incident, investigate the key environment conditions and prevent secondary event, and protect hazard-affected carriers. Take three kinds of consequences Casualties, Economic Loss and Environment Pollution as the targets to analyze the effect of "Emergency Response". The result is listed in Table 2. It is obvious that the more effective emergency response is, the less consequences will be caused.
Table 2. The Effect of Emergency Response to Consequences.

\begin{tabular}{|c|c|c|c|c|}
\hline \multirow{2}{*}{\multicolumn{2}{|c|}{ Probability (\%) }} & \multicolumn{3}{|c|}{ Emergency Response } \\
\hline & & \multirow{2}{*}{$\begin{array}{c}\begin{array}{c}\text { Effecti } \\
\text { ve }\end{array} \\
14.9\end{array}$} & \multirow{2}{*}{$\begin{array}{c}\begin{array}{c}\text { Gener } \\
\text { al }\end{array} \\
12.0\end{array}$} & \multirow{2}{*}{$\begin{array}{l}\text { Poor } \\
9.21\end{array}$} \\
\hline Casualties & (1) $<5$ persons & & & \\
\hline & $\begin{array}{l}\text { (2) } 5 \text { to } 10 \\
\text { persons }\end{array}$ & 22.0 & 16.9 & 17.4 \\
\hline & $\begin{array}{l}\text { (3) } 10 \text { to } 30 \\
\text { persons }\end{array}$ & 31.1 & 31.7 & 30.1 \\
\hline & (4) $>30$ persons & 32.0 & 39.4 & 43.3 \\
\hline \multirow[t]{4}{*}{$\begin{array}{l}\text { Economic } \\
\text { Loss }\end{array}$} & (1) $<1$ million & 45.0 & 3.86 & 0.66 \\
\hline & (2) 1 to 5 million & 43.2 & 19.4 & 7.25 \\
\hline & (3) 5 to 10 million & 11.3 & 38.8 & 17.4 \\
\hline & (4) $>10$ million & 0.51 & 38.0 & 74.4 \\
\hline \multirow[t]{4}{*}{$\begin{array}{l}\text { Environm } \\
\text { ent } \\
\text { Pollution }\end{array}$} & $\begin{array}{l}\text { (1) }<1 \mathrm{~km}^{2} \text { water } \\
\text { area }\end{array}$ & 21.2 & 3.72 & 0 \\
\hline & $\begin{array}{l}\text { (2) } 1 \text { to } 10 \mathrm{~km}^{2} \\
\text { water area }\end{array}$ & 30.0 & 33.3 & 33.5 \\
\hline & $\begin{array}{l}\text { (3) } 10 \text { to } 50 \mathrm{~km}^{2} \\
\text { water area }\end{array}$ & 34.5 & 38.1 & 34.4 \\
\hline & $\begin{array}{l}\text { (4) }>50 \mathrm{~km}^{2} \\
\text { water area }\end{array}$ & 14.2 & 24.9 & 32.2 \\
\hline
\end{tabular}

\section{Conclusion}

This paper introduces a quantitative analysis model of the risk factors that affect oil pipeline network accident. It uses the incident evolution diagram to illustrate the process of incidents and to identify risk factors. Based on Bayesian model, the incident consequences can be estimated, and the risk factors' effects can be analyzed quantitatively.

In the oil pipeline accident case, the most likely consequences are consilient with the case. As the emergency resources are limit, the quantitative analysis results may provide a theoretical basis to take effective risk treatment measures for oil pipeline management, which can be used in emergency preparation and emergency response.

\section{Acknowledgments}

The authors deeply appreciate support for this paper by the National Natural Science Foundation of China (Grant No. 71673161), and the Fundamental Research Funds for the Central Business Unit (Grant No. 512015Y-4002). 


\section{References}

1. W. Liang, J. Hu, C. Guo, et al, Eng. Appl. Artif. Intell 25, 3 (2012)

2. S. Doug, V. Brian, K. Faisal, et al, J. Loss Prev. Process Ind 45 (2017)

3. M. Bertolini, M. Bevilacqua, J. Qual. Maint. Eng 12, 2 (2016)

4. D. Wang, E. Liu, L. Huang, Open Civ. Eng. J 11, 1 (2017)

5. P. Jia, Y.U. Xiao, Q. Song, Ind. Saf. Environ. Prot 40, 2 (2014)

6. M.V.P. Muniz, G.B.A. Lima, Process Saf. Prog 7 (2017)

7. K. Peter, L. Buzna, D. Helbing, Int. J. Crit. Infrastruct, 4 (2008)

8. S.A. Joseph, B.J. Adams, B. McCabe, J. Infrastruct. Syst 16 (2010)

9. Z. Yuan, N. Khakzad, F. Khan, et al, Risk Anal 352 (2015)

10. G. Kabir, R. Sadiq, S. Tesfamariam, Struct. Infrastruct. Eng 12 (2016)

11. X.H. Li, G.M. Chen, H.W. Zhu, Process Saf. Environ. Prot 103 (2016)

12. A.P. Dempster, Classic Works of the DempsterShafer Theory of Belief Functions (Springer, Berlin Heidelberg, 2008)

13. J. Wu, R. Zhou, S. Xu, et al, J. Loss Prev. Process Ind 46 (2017) 